"Thank you," he said, "Thank you!"

"And now" continued Holmes, "Might I suggest you hurry along to see $\mathrm{Mr}$ Trade in his office next door, for it is he whom you must persuade of your purpose."

"Les Trade? The Head Porter!" queried Moriarty.
"Not since The Triformation," returned Holmes, showing the contented consultant out. "He is now Chief Inspector Les Trade of the Continuous Improvement Directorate. Watson, be so kind as to pass me the audit figures. I have a need to play the fiddle."

\title{
The arrogance of insight?
}

\author{
Rachel Perkins, Consultant Clinical Psychologist, Springfield University Hospital; \\ and Parimala Moodley, Senior Lecturer in Community Mental Health, \\ Institute of Psychiatry and The Maudsley Hospital, Denmark Hill, London SE5 8AF
}

People's beliefs about illness, distress and disability profoundly influence their experience of, and responses to, such problems. Medical anthropologists have long recognised the importance of explanatory models of physical illness and the impact of these on the provision and use of health services. Similarly, psychological models of physical illness and related behaviour stress the importance of the ways in which people conceptualise or understand their difficulties. These are central in determining emotional responses to illness, help-seeking and illness-related behaviours, attitudes towards and compliance with treatment. Eisenbruch (1990) argues that, "the culturally constructed ideas held by the patient about the cause and nature of disease" are as important in relation to mental distress and disturbance. Help-seeking behaviour, attitudes towards and compliance with treatment are of central concern in psychiatry and all of these are influenced by people's understandings of their difficulties. Yet relatively little attention has been paid to the ways in which people conceptualise their mental distress.

Typically, mental health professionals make use of the concept of insight. A person's understanding of their problem is seen as symptomatic of their condition. Despite suggestions that this concept of insight is of limited value, it is still very much alive in current clinical practice.

David (1990) has argued that the concept of insight should be elaborated and extended. In particular, he argues that insight should not be seen as an all-or-nothing phenomenon and that it comprises three distinct, but overlapping, dimensions: the recognition that one has a mental illness, compliance with treatment, and the ability to relabel unusual mental events as pathological. Such a 'reformation' does indeed make more specific the 'correct' attitude to which Aubrey Lewis referred in defining insight as "a correct attitude to morbid change in oneself" (Lewis, 1934), and could undoubtedly lead to a more uniform and less confused use of the concept. However, it does make more specific the value judgements and framework within which the concept gains its meaning.

In David's (1990) formulation insight means not only agreeing with the doctor that one is mentally ill, but agreeing with the remediation for that illness (as defined within a psychiatric framework), and reconstructing one's experience with the terms and concepts of Western psychiatry, rather than one's karma or bodily imbalance or disharmony. Several studies have shown that around half of those people admitted to psychiatric hospital lack insight in that they do not consider themselves to have a mental illness (see Moodley \& Perkins, 1991 a \& b). Clearly, a significant proportion of newly admitted psychiatric patients do not concur with a psychiatric view of their difficulties.

Insight is an extremely crude concept and offers an extremely limited index of the way a person understands their distress and disturbance. David's (1990) elaboration does not change this. There are many different frameworks within which people understand their difficulties (Eisenbuch, 1990; Moodley \& Perkins, 1991a \& b). Some adopt religious explanations of their world, while others use models couched in physical processes, or social/interpersonal explanatory frameworks. It is not the case that a person uses a single explanatory framework. As in other areas of human experience, a single individual may simultaneously hold a range of different and sometimes mutually incompatible 
frameworks (e.g. science and religion). In order fully to understand, and be in a position to assist a person with their difficulties, clinicians must be able to explore, and help their clients to articulate such varied conceptualisations. To reduce all such exploration to a single scale of insight is neither illuminating nor useful.

Predicated as it is on a Eurocentric view of the world, the concept of insight in psychiatry is essentially arrogant. In a society that encompasses a wide variety of different beliefs and values, it accords pride of place to a single, rather narrow, perspective - that of 'scientific psychiatry'. Despite social psychiatry's long recognition of the importance of the cultural context in understanding distress and disturbance, the considerable progress made in transcultural psychiatry, and the work of medical anthropologists, the concept of insight persists in psychiatric training and much service provision. It is this latter context that is the most disturbing.

There is an increasing emphasis on the user in psychiatric service provision, and in particular, on making services acceptable and accessible to the range of people who need them. Often accessibility and acceptability are seen in terms of geographical location, physical appearance, opening hours and waiting times. The attitudes, approaches and perspectives adopted are equally, if not more important. Services that are perceived as relevant are those which are compatible with their users' perspectives, beliefs and values. To persist in believing that one construction of problems is 'correct' means that those users who do not hold this 'correct' perspective will be alienated from those very services which they need.

This is not to say that people do not experience distress and disturbance, nor that they do not require specialist help. Rather, that there is a range of models within which this help can be framed, understood, and provided. Services must be sensitive to the varied beliefs and values of their users. Concepts like insight perpetuate arrogant, provider lead, models of service which can never really meet the needs of those they serve.

\section{References}

DAvid, A. S. (1990) Insight and psychosis. British Journal of Psychiatry, 156, 798-808.

EISENBRUCH, M. (1990) Classification of natural and supernatural causes of mental distress. Journal of Nervous and Mental Disease, 178, 712-719.

LEWIS, A. (1934) The psychopathology of insight. British Journal of Medical Psychology, 14, 332-348.

MoOdley, P. \& Perkins, R. E. (1991a) Perception of problems in psychiatric inpatients: race, denial and service usage, Paper presented at the Biennial Congress of the World Federation for Mental Health, Mexico City.

- \& - (1991b) Routes to psychiatric inpatient care in an Inner London Borough. Social Psychiatry and Psychiatric Epidemiology, 26, 47-51.

A full list of references is available from the authors. 